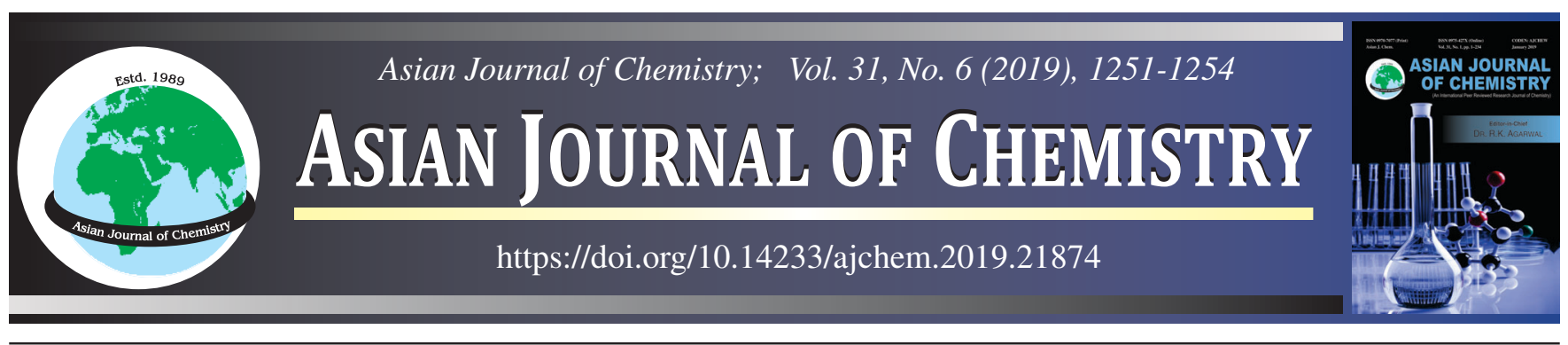

\title{
Experimental Study on Change in Mechanical Characteristics of E-Glass Fibre Reinforced Epoxy Composite by Adding Carbon Nanotube Layers
}

\section{Albert Allen ${ }^{1}$, G. Ramanan ${ }^{1, *, 0}$, R.R. Neela Rajan ${ }^{2}$ and A.K. Darwins ${ }^{3}$}

${ }^{1}$ Department of Aeronautical Engineering, ACS College of Engineering, Bangalore-560074, India

${ }^{2}$ Department of Aeronautical Engineering, Noorul Islam Centre for Higher Education, Nagercoil-629180, India

${ }^{3}$ Department of Mechanical Engineering, Noorul Islam Centre for Higher Education, Nagercoil-629180, India

*Corresponding author: E-mail: gramanan1987@gmail.com

Received: 12 December 2018;

Accepted: 25 January 2019;

Published online: 29 April 2019;

AJC-19364

Polymer composite reinforced with fiber materials have always proven its superior significant enactment over numerous traditional materials, considering their incomparable strength to weight ratio and stiffness. Carbon nanotubes usage in glass-fiber reinforced polymer has high potential in changing the characteristics of composite laminates. Carbon nanotubes have engrossed composite fraternity in exploring the opportunity of utilizing them as a supplementary reinforcement in fiber reinforced polymer composites. This study examines the mechanical characters of glass-fiber reinforced polymer with and without multi-walled carbon nanotubes (MWCNT). Composite laminated layers are fabricated using epoxy resin without carbon nanotube and with 0.5 and $1.5 \%$ MWCNT. The materials were tested to determine tensile, flexural and compression properties. It is observed that the carbon nanotubes can enhance the mechanical properties in the composite laminates. Composite laminate with $1.5 \mathrm{wt} \%$ MWCNT exhibited good mechanical properties compared to that with $0.5 \mathrm{wt}$ $\%$ MWCNT and without MWCNT.

Keywords: Composites, Carbon nanotubes, Mechanical Characteristics, Glass-fiber reinforced polymer.

ᄂ - - - - - - - - - - - - - - - - - - - - - - - - - -

\section{INTRODUCTION}

From the past few years, composite materials are extensively used in various engineering field like civil constructions, aerospace applications and automotive industries due to their high-quality characteristics of light weight, corrosion resistance, improved strength, controllable anisotropic properties, less manufacturing cost and maintenance cost. However, there is a rising demand to produce more improved composite materials within the reasonable cost of construction $[1,2]$. The use of fillers, metals and fibers in the thermoplastics and thermosets for spans to form composites. In compassion with neat resins, these composites illustrate a number of enhanced mechanical properties, which includes distortion, tensile strength and modulus. Therefore, for structural applications, composites are extensively used have turn out to be highly popular [3]. Advanced composite materials are preferred to use while manufacturing spacecraft components in the present demanding environments. Engineered composite materials must be formed to desired shape and size. This involves advantageously arranging the reinforcements while covering the matrix material to achieve the intended property, which is at or near the being of expected component life [4]. The different available methods are used in accordance to obtain the desired design requirements. Yip et al. [5] reported the fabrication method of CNTs/ GFRP composite laminates using ultrasonication process and hand lay-up technique. When CNT content is $0.75 \%$ hundred resins, the mechanical properties are the best. The ILSS was significantly improved $15.7 \%$ and flexural strength upgraded $9.2 \%$. Khomane and Raut [6] discussed the characterization of epoxy based composite materials for the applications where strength to weight ratio is the primary design parameter weight and high strength application. He also analyzed the fiber volume fraction of the composites with operative consolidation (low thickness) of layers by applying vacuum and pressure throughout laminate curing. Mahdi et al. [7] studied the characterization of carbon fiber reinforced epoxy composites modified by the introduction of nanoclay and CNTs. In this study, 2 wt.

This is an open access journal, and articles are distributed under the terms of the Creative Commons Attribution-NonCommercial-ShareAlike 4.0 (CC BY-NC-SA 4.0) International License which allows readers to freely read, download, copy, distribute, print, search, or link to the full texts of its articles and to use them for any other lawful non-commercial purpose as long as the original source is duly acknowledged. 
$\%$ montmorillonite nanoclay and $0.3 \mathrm{wt}$. \% multi-walled carbon nanotubes (MWCNTs) were used with carbon fiber reinforced epoxy composites. Chandra Shekar et al. [8] studied the interlaminar shear strength of multi-walled carbon nanotubes and carbon fiber reinforced, epoxy-matrix hybrid composite. The results illustrate the substantial escalation in inter-laminar shear strength of the hybrid composite with orientation that is longitudinal as connected to transverse orientation; and more significantly highlights that such anisotropy is of an order of higher magnitude [9]. The objective of the current research is to examine the mechanical properties of glass fiber reinforced epoxy polymer with and without the carbon nanotube filler material. This work is believed to be helpful for understanding the effect of different amount of filler in G-E composite. In view of the above, the main objective of this work is to fabrication of glass fiber reinforced epoxy resin composites and bidirectional glass fiber reinforced epoxy resin composite with and without carbon nanotube filler content are fabricated by hand lay-up process [10]. To evaluate the mechanical properties of glass fiber rein-forced epoxy composite with and without carbon nanotubes filler and mechanical properties like flexural strength, compressive strength and tensile strength are evaluated using graphical interpretation.

\section{EXPERIMENTAL}

Epoxy LY556 and hardener HY951 were used as matrix material for reinforced composites in this work. The main reason epoxy resin was used as polymer matrix since it is known that CNTs gets dispersed in a better way in the epoxy resin when judged against other polymer resins.

E-Glass fiber (300GSM): Woven bidirectional E-glass fiber of mass 300GSM was used as reinforcing material. Each ply thickness was $0.28 \mathrm{~mm}$. The fibers in a bidirectional arrangement are in two directions - habitually at $90^{\circ}$ to each other in the idea of providing the greatest strength in those directions. The identical number of fibers need not unavoidably be utilized in both directions [11]. High fiber loading could be obtained in woven bidirectional reinforcements. E-glass is the standard form and is also recognized as electrical grade, which possess alkali content at low level and good mechanical, chemical and electrical properties. E-Glass is a low alkali glass with a typical nominal composition of $\mathrm{SiO}_{2}(54 \%), \mathrm{Al}_{2} \mathrm{O}_{3}(14 \%), \mathrm{CaO}+$ $\mathrm{MgO}(22 \%), \mathrm{B}_{2} \mathrm{O}_{3}(10 \%)$ and $\mathrm{Na}_{2} \mathrm{O}+\mathrm{K}_{2} \mathrm{O}$ less than $2 \%$. Some other materials also exist as impurities are shown in Table-1.

Multi walled carbon nanotube (MWCNT): MWCNT is a filler material, which acts as an additional reinforcing component. Accumulation of nanoparticle to glass-fiber reinforced polymer laminate raises the mechanical properties not only tensile strength but also the tensile modulus without substantial weight addition. Because of the excellent mechanical, thermal and electrical properties of carbon nanotubes have fascinated composite fraternity in exploring the possibility of utilizing them as an added reinforcement in fiber reinforced polymer composites [12]. Raw materials used in this work are resinepoxy LY556, hardner-HY951, E-glass fabric woven sheet, filler-carbon nanotube and acetone.

Methods: The base plate was cleaned with acetone. EpoxyLY556 (resin) was heated for a certain period of time to reduce the viscosity. After attaining particular viscosity carbon nanotube was added continuously and the mixture was stirred mechanically at $450 \mathrm{rpm}$ until it reached at room temperature. HardnerHY951 was then added in the ratio of 100:10. A mixture of epoxy resin, hardener and carbon nanotube filler forming a matrix was thus prepared in the prescribed ratio and required wt $\%$ [13]. The glass fabric sheet was placed and the matrix mixture was spread uniformly using brush. The wetting of the glass fabric by applying the matrix mixture on each ply was continued until the required thickness was obtained. Total 10 layers of glass ply were used. Vacuum bagging was carried out by applying one atmospheric pressure onto the system. The laminate was cured at room temperature for $24 \mathrm{~h}$. Post curing was then carried out for $2 \mathrm{~h}$ at $100{ }^{\circ} \mathrm{C}$ in an oven.

By following the same procedure, composite material with and without filler material was prepared. A polythene sheet which is a non-perforated release film is used to hold the resin and for the easy removal of the laminate. For vacuum bagging a Teflon paper which is a perforated release film or peel-ply material is used in removing excess of resin from the laminate. A Teflon paper, which is a perforated release film or peel-ply material is used in removing excess of resin from the laminate. The next layer added is the bleeder/breather material. As its name implies, this material offers two significant functions. First, it engrosses surplus resin from the laminate. It ensures that the vacuum is dispersed evenly within the bag. Now surface bagging is carried out. Around the laminate's perimeter, sealant tape is attached to the base structure with an inch overlap at all four corners. Succeeding the vacuum coupling is inserted. On removing the paper strip from one line of the sealant tape and the bag gets closed to the exposed sealant. Vacuum is applied when the bag find its place.

Testing of composite materials: Tensile testing was carried out for the micro tensile test specimens with dimension of 250 $\mathrm{mm} \times 25 \mathrm{~mm} \times 3 \mathrm{~mm}$ as per the ASTM-D3039. The test specimen is positioned vertically in the grips of the testing machine.

Flexural testing: A point is reached before the breaking point, by the material in order to withstand the bending. Predictably a three point bend test is performed to determine this material property. Flexural test has been done with ASTM-D3029 standard with dimensions of $125 \mathrm{~mm} \times 12.7 \mathrm{~mm} \times 3.2 \mathrm{~mm}$.

Compression testing: Compression testing was carried out for ASTM-6641 standard test specimens. Compressive properties pronounce the material behaviour when it is exposed to a compressive load. At uniform rate, the specimen with 150 $\mathrm{mm} \times 12.25 \mathrm{~mm} \times 3.2 \mathrm{~mm}$ specification is compressed. The maximum load is documented along with stress-strain data. An extensometer attached to the front of the fixture is used in determining modulus.

TABLE-1 PERCENTAGE COMPOSITION OF E-GLASS

\begin{tabular}{ccccccccccc}
\hline $\mathrm{SiO}_{2}$ & $\mathrm{Al}_{2} \mathrm{O}_{3}$ & $\mathrm{CaO}$ & $\mathrm{MgO}$ & $\mathrm{B}_{2} \mathrm{O}_{3}$ & $\mathrm{~K}_{2} \mathrm{O}$ & $\mathrm{Na}_{2} \mathrm{O}$ & $\mathrm{F}_{2} \mathrm{O}_{3}$ & $\mathrm{TiO}_{2}$ & $\mathrm{~F}_{2}$ \\
\hline $52-56$ & $12-16$ & $16-25$ & $0-5$ & $8-13$ & $0-1.5$ & $0-1.5$ & $0.05-0.4$ & $0-0.8$ & $0-0.5$ \\
\hline
\end{tabular}




\section{RESULTS AND DISCUSSION}

Experiments were performed in characterizing the prepared composite material under varying loading conditions along with numerous specimen configurations. Beside those properties, the interfacial bonds nature and the load transfer mechanisms at the inter phase too perform a significant role. Result analysis and the influence of numerous parameters on the properties are shortened in the succeeding sections. After carrying out the above mechanical experiments it was seen that the tensile, flexural and compression strength increased with the addition of MWCNT. The enhancements in mechanical properties attribute to the dispersion of MWCNT and the interfacial adhesion between epoxy matrix and MWCNT so that the chain matrix mobility is controlled under loading. The strong interfacial interaction that exist in the composites may also limit the matrix mobility in the interface among the fiber and the matrix and the matrix permitting improved stress transfer to the glass fibers within the composite.

Tensile behaviour of composite: Three specimens from each variation of the composite have been tested. Dimensions of the test coupons were $250 \mathrm{~mm}$ in length, $25 \mathrm{~mm}$ in width and $3 \mathrm{~mm}$ in thickness correspondingly. Average modulus for the glass-carbon epoxy composite with and without fillers has been determined to be $2.44,3.03$ and $2.16 \mathrm{MPa}$, respectively. The tensile test results with carbon nanotubes are given in Table-2. It is concluded that the average modulus of elasticity will be increased by $19.44 \%$ between the hybrid composite samples made from without MWCNT and with MWCNT [13].

Flexural properties: Carbon fiber reinforced composites altered with nanoparticles are made to undertake three point bending load in the idea of comparing the flexural properties of nanoparticles modified ones to control one. Tables 3 and 4 shows the effect of nanoparticles on the flexural properties of composites. Flexural strength and all the samples modulus values goes up with adding of nanoparticles and the enhancement were practically similar.

\section{Conclusion}

Based on the test outcomes achieved from the numerous tests performed, the succeeding inferences were made:

Out of the tensile tests carried out on the test specimens, it was noted that the elastic strength of the material increases with the addition of MWCNT fibres. Also the ultimate stress for the glass fiber epoxy with and without MWCNT was found to be $0.419 \mathrm{KN} / \mathrm{sq} . \mathrm{mm}, 0.458 \mathrm{KN} / \mathrm{sq} . \mathrm{mm}$ and $0.469 \mathrm{KN} /$ sq.mm, respectively and thus the strength increases with the increase in percentage of MWCNT present in the material.

From the flexural tests carried out on the specimens, it was noted that the maximum bending moment increases with the addition of MWCNT and it increases with the percentage increase of MWCNT in the material.

From the compression tests carried out, it was seen that the compressive strength of the material increases with the addition of MWCNT to the material and increases with the increase in the percentage of MWCNT in the material. The overall mechanical properties of the material are noted to be improved by the addition of MWCNT to the material.

\section{CONFLICT OF INTEREST}

The authors declare that there is no conflict of interests regarding the publication of this article.

TABLE-2

TENSILE TEST RESULTS OF COMPOSITES WITH NANOTUBES

\begin{tabular}{|c|c|c|c|c|c|c|c|c|c|}
\hline \multirow{2}{*}{$\begin{array}{l}\text { Specimen/ } \\
\text { Load }\end{array}$} & \multicolumn{3}{|c|}{ Breaking load $(\mathrm{KN})$} & \multicolumn{3}{|c|}{ Ultimate stress (KN/sq.mm) } & \multicolumn{3}{|c|}{ Yield stress (KN/sq.mm) } \\
\hline & No CNT & 0.5 & 1.5 & No CNT & 0.5 & 1.5 & No CNT & 0.5 & 1.5 \\
\hline Specimen 1 & 22.740 & 13.060 & 18.840 & 0.396 & 0.441 & 0.452 & 0.217 & 0.245 & 0.228 \\
\hline Specimen 2 & 16.220 & 18.940 & 38.220 & 0.399 & 0.426 & 0.510 & 0.218 & 0.234 & 0.303 \\
\hline Specimen 3 & 34.740 & 38.020 & 33.380 & 0.463 & 0.507 & 0.445 & 0.299 & 0.287 & 0.236 \\
\hline Avg. results & 24.567 & 23.340 & 30.147 & 0.419 & 0.458 & 0.469 & 0.245 & 0.255 & 0.256 \\
\hline
\end{tabular}

TABLE-3

BENDING TEST RESULTS FOR COMPOSITES WITH NANOTUBES

\begin{tabular}{|c|c|c|c|c|c|c|c|c|c|}
\hline \multirow{2}{*}{ Specimen } & \multicolumn{3}{|c|}{ Breaking load $(\mathrm{KN})$} & \multicolumn{3}{|c|}{ Young's modulus (KN/sq.mm) } & \multicolumn{3}{|c|}{ Maximum bending moment (KN.mm) } \\
\hline & No CNT & 0.5 & 1.5 & No CNT & 0.5 & 1.5 & No CNT & 0.5 & 1.5 \\
\hline Specimen 1 & 4.26 & 4.26 & 4.36 & 33.41 & 33.42 & 36.93 & 39.78 & 40.68 & 41.04 \\
\hline Specimen 2 & 4.30 & 4.44 & 4.26 & 32.45 & 48.68 & 39.62 & 41.22 & 41.22 & 41.94 \\
\hline Specimen 3 & 4.22 & 4.06 & 4.45 & 31.66 & 32.46 & 49.24 & 38.69 & 39.69 & 42.68 \\
\hline Average results & 4.26 & 4.25 & 4.35 & 32.50 & 38.19 & 41.93 & 39.89 & 40.53 & 41.88 \\
\hline
\end{tabular}

TABLE-4

COMPRESSION TEST RESULTS

\begin{tabular}{|c|c|c|c|c|c|c|c|c|c|}
\hline \multirow{2}{*}{ Specimen } & \multicolumn{3}{|c|}{ Peak load $(\mathrm{KN})$} & \multicolumn{3}{|c|}{ Breaking load $(\mathrm{KN})$} & \multicolumn{3}{|c|}{ Ultimate stress (KN/Sq.mm) } \\
\hline & No CNT & 0.5 & 1.5 & No CNT & 0.5 & 1.5 & No CNT & 0.5 & 1.5 \\
\hline Specimen 1 & 7.560 & 7.340 & 7.760 & 4.800 & 5.020 & 5.880 & 0.198 & 0.193 & 0.204 \\
\hline Specimen 2 & 7.480 & 7.680 & 7.810 & 4.960 & 5.210 & 5.780 & 0.186 & 0.181 & 0.213 \\
\hline Specimen 3 & 7.610 & 7.780 & 7.710 & 4.710 & 5.110 & 5.680 & 1.183 & 0.173 & 0.221 \\
\hline Average results & 7.550 & 7.600 & 7.760 & 4.823 & 5.113 & 5.780 & 0.522 & 0.183 & 0.213 \\
\hline
\end{tabular}




\section{REFERENCES}

1. K. Friedrich, Adv. Ind. Eng. Polym. Res., 1, 3 (2018); https://doi.org/10.1016/j.aiepr.2018.05.001.

2. N. Saba and M. Jawaid, J. Ind. Eng. Chem., 67, 1 (2018); https://doi.org/10.1016/j.jiec.2018.06.018.

3. A.K. Darwins, M. Satheesh and G. Ramanan, IOP Conf. Series Mater. Sci. Eng., 402, 012162 (2018); https://doi.org/10.1088/1757-899X/402/1/012162.

4. M.E. Islam, T.H. Mahdi, M.V. Hosur and S. Jeelani, Procedia Eng., 105, 821 (2015); https://doi.org/10.1016/j.proeng.2015.05.078.

5. M.-C.Yip, Y.-C. Lin and C.-L. Wu, Polym. Polym. Compos., 19, 131 (2011); https://doi.org/10.1177/0967391111019002-313.

6. S.M. Khomane and L.B. Raut, Int. Adv. Res. J. Sci. Eng. Technol., 3, 178 (2016)

7. T.H. Mahdi, M.E. Islam, M.V. Hosur and S. Jeelani, J. Reinforced Plast. Compos., 36, 696 (2017); https://doi.org/10.1177/0731684417693429.
8. K. Chandra Shekara, A. Prasad and N.E. Prasad, Procedia Mater. Sci., 6, 1336 (2014); https://doi.org/10.1016/j.mspro.2014.07.112.

9. S. Sivasaravanan, V.B. Raja and Manikandan, Procedia Eng., 97, 968 (2014);

https://doi.org/10.1016/j.proeng.2014.12.373.

10. G. Ramanan, G.D. Samuel, S.M. Sherin and K. Samuel, IOP Conf. Series Mater. Sci. Eng., 402, 012163 (2018); https://doi.org/10.1088/1757-899X/402/1/012163.

11. K.P. Ashik, R.S. Sharma and N. Raghavendra, Asian J. Chem., 29, 1697 (2017): https://doi.org/10.14233/ajchem.2017.20551.

12. M.N. Salimi, M.T. Merajin and M.K.B. Givi, J. Compos. Mater, 51, 745 (2017); https://doi.org/10.1177/0021998316655201.

13. N. Abilash and M. Sivapragash, Eng. Sci. Technol. Int. J., 3, 7 (2013). 